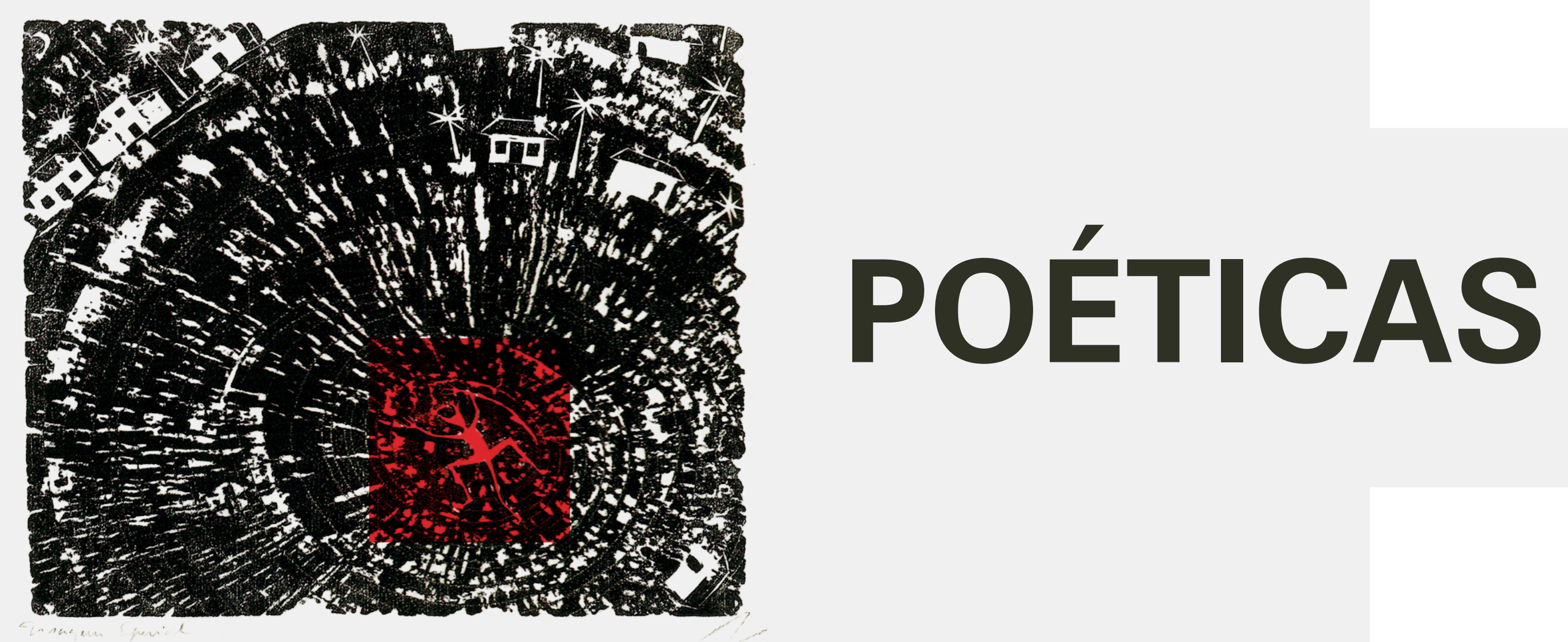




\section{IMAGENS DO GRANDE SERTÃO}

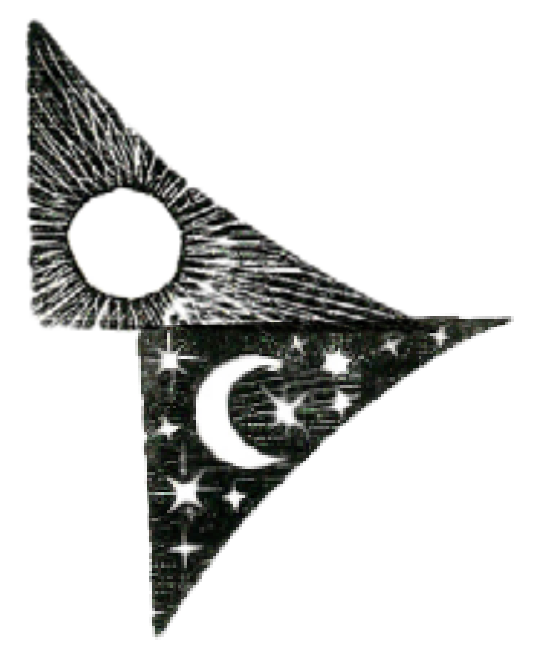

Arlindo Daibert

O artista Arlindo Daibert (1952-1993) fez de sua obra um intenso diálogo
com a literatura, explorando, de modo crítico, a relação entre as lingua-
gens verbais e visuais. A série dedicada a Grande Sertão: Veredas, criada
ao longo de aproximadamente uma década, é composta de 20 xilogravu-
ras e 50 desenhos, nos quais, mais do que uma interpretação ou ilustração
do texto, encontramos uma pesquisa conceitual a respeito do universo
simbólico que caracteriza a obra de Guimarães Rosa. A multiplicidade
de recursos e técnicas, como a xilogravura, a colagem, a aquarela e o
desenho, dá a ver a busca pela diversidade material entrevista na própria
construção literária, e responde, de modo mais amplo, à investigação das
potencialidades de cada linguagem. 


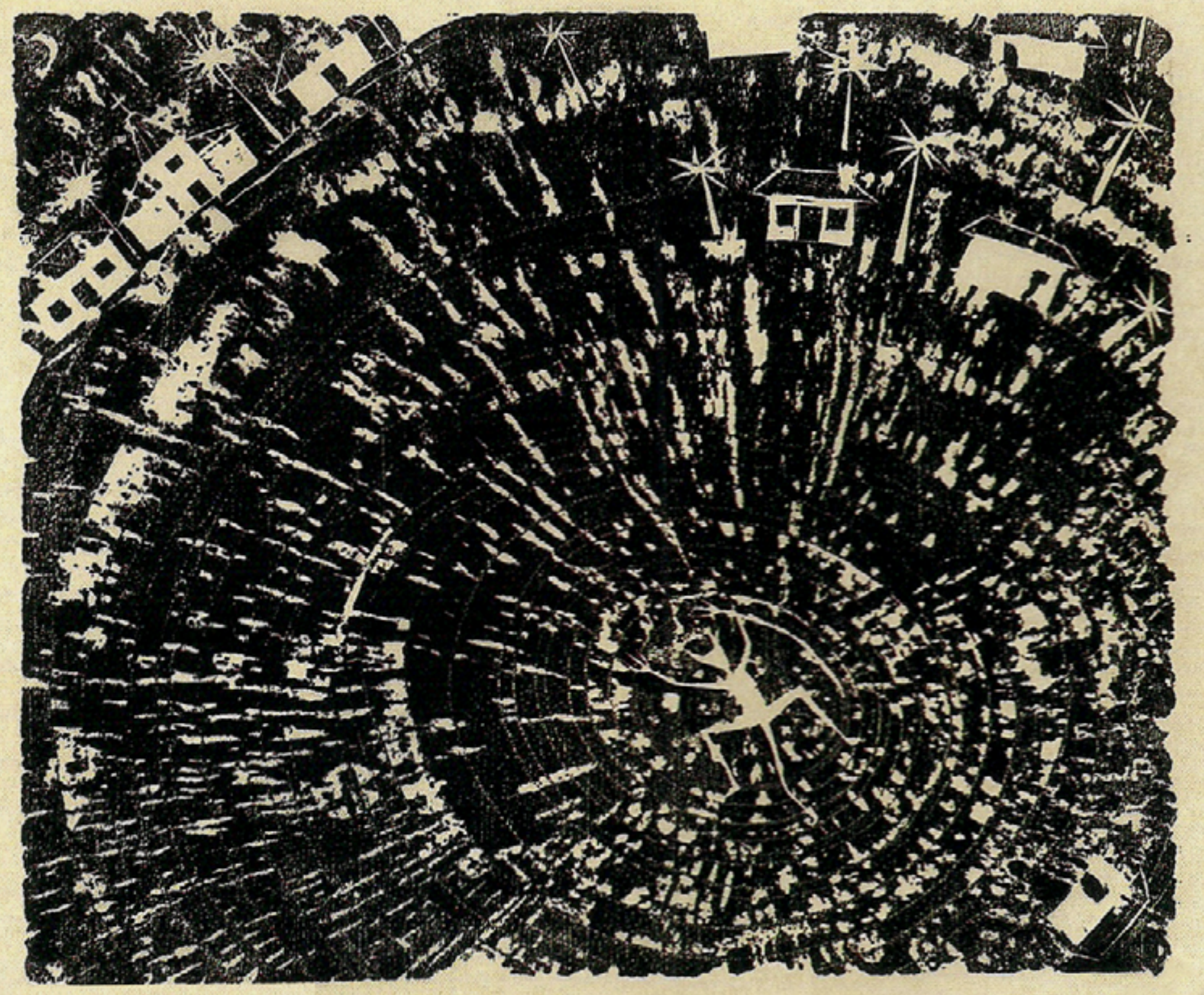

"...No meio do redemoinho" 


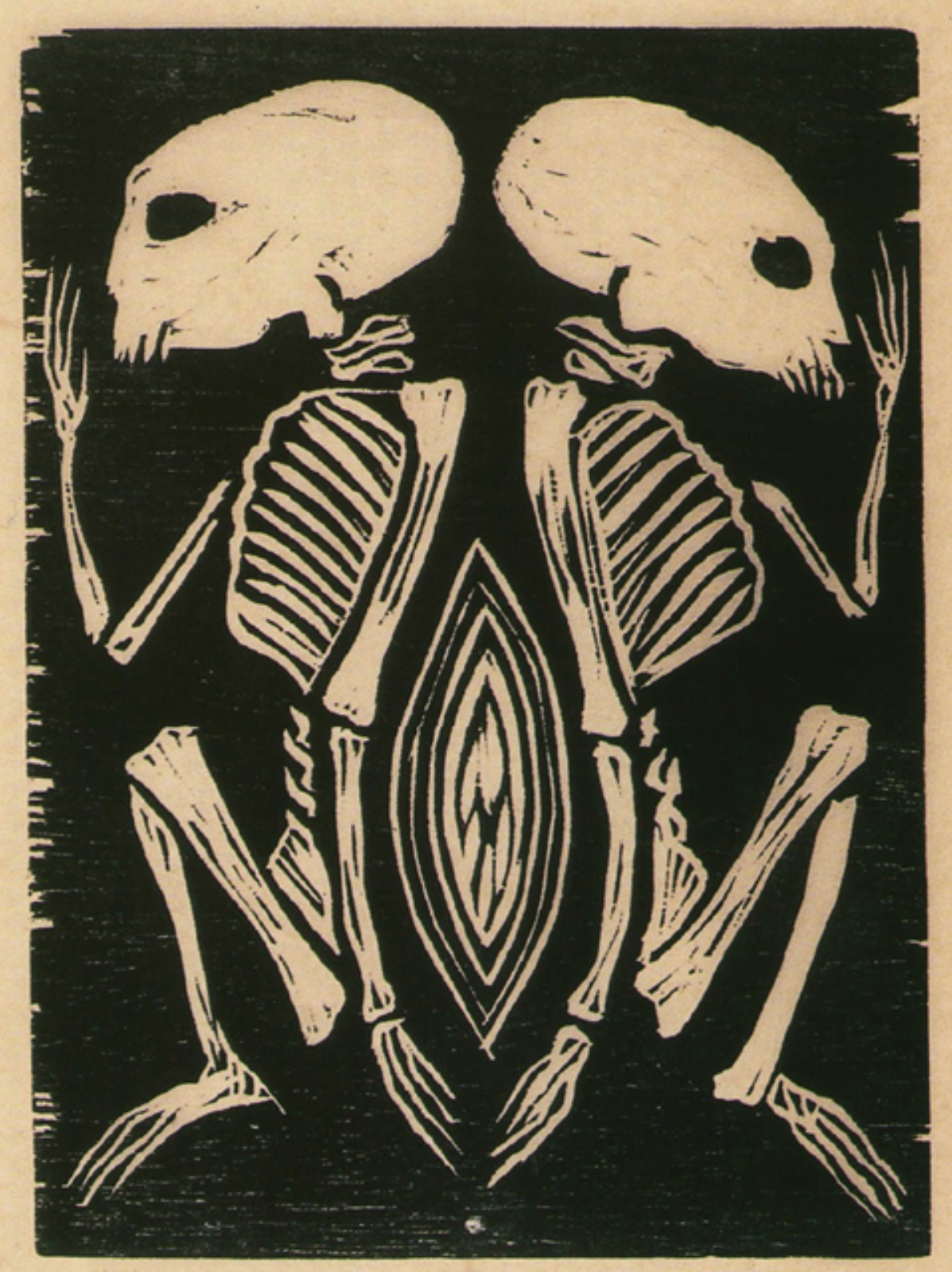

A Deus dada

Xilogravura, tiragem especial P.A.II 


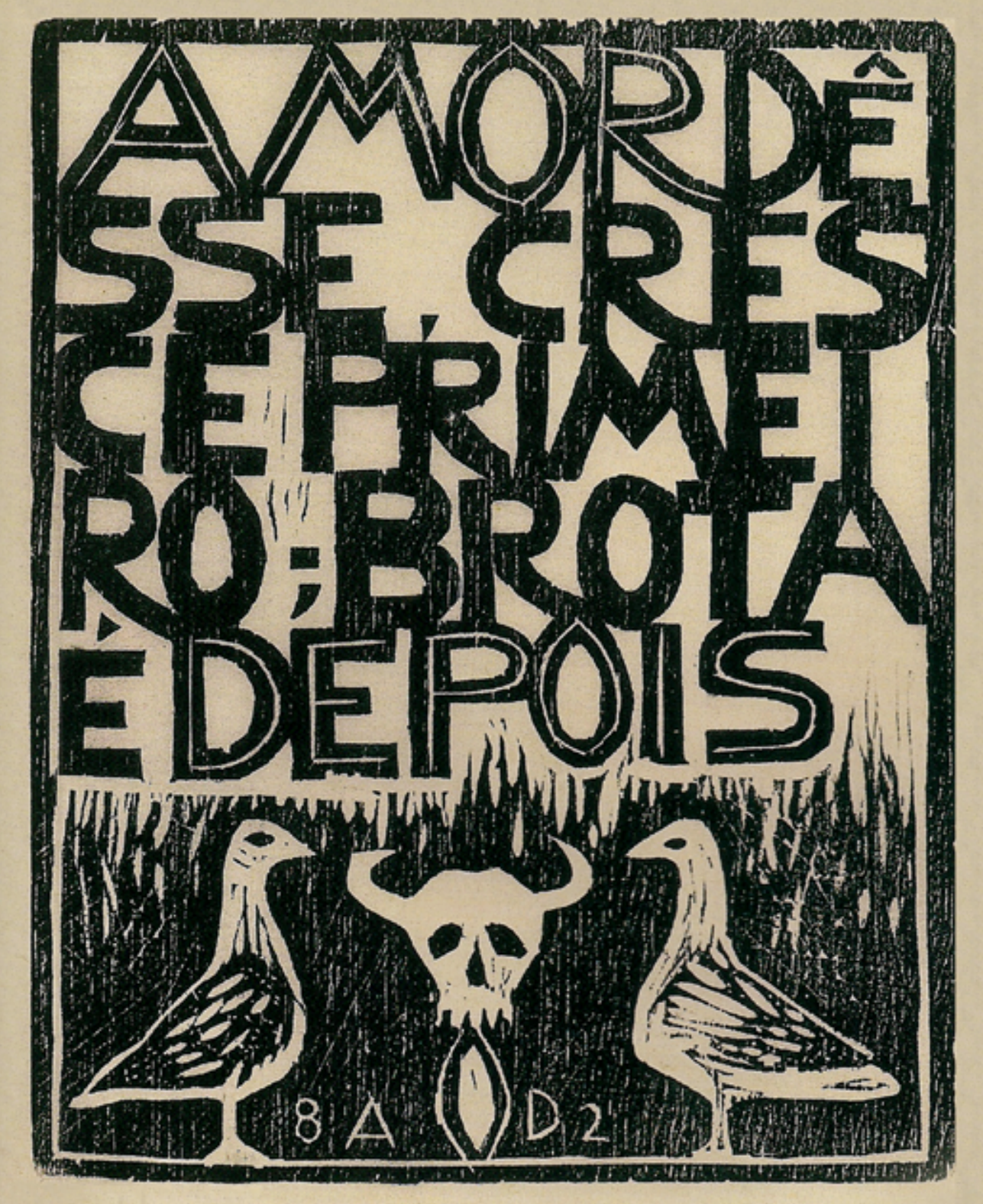




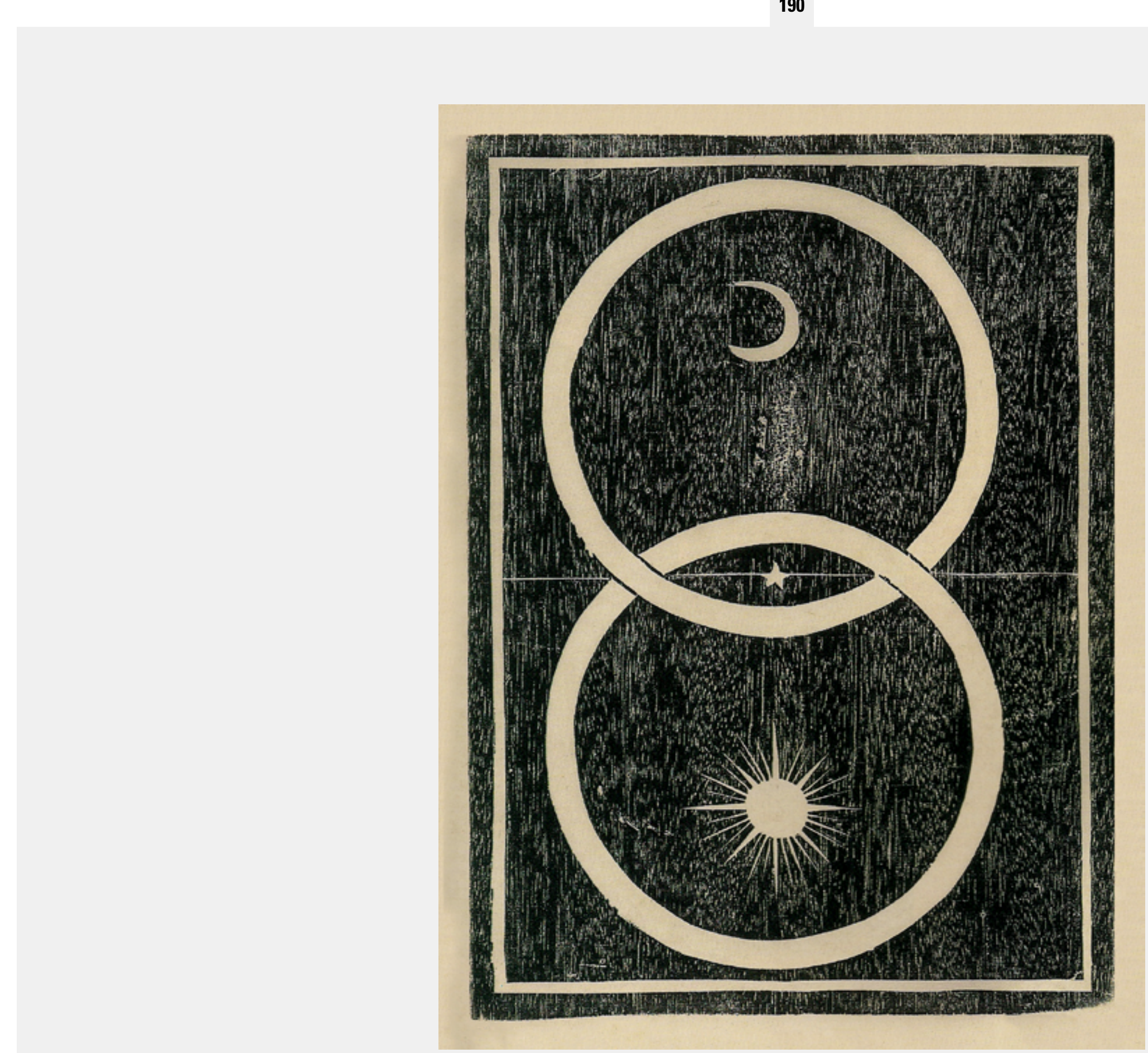

Diadorim II

Xilogravura, tiragem especial P.A.II 1984 

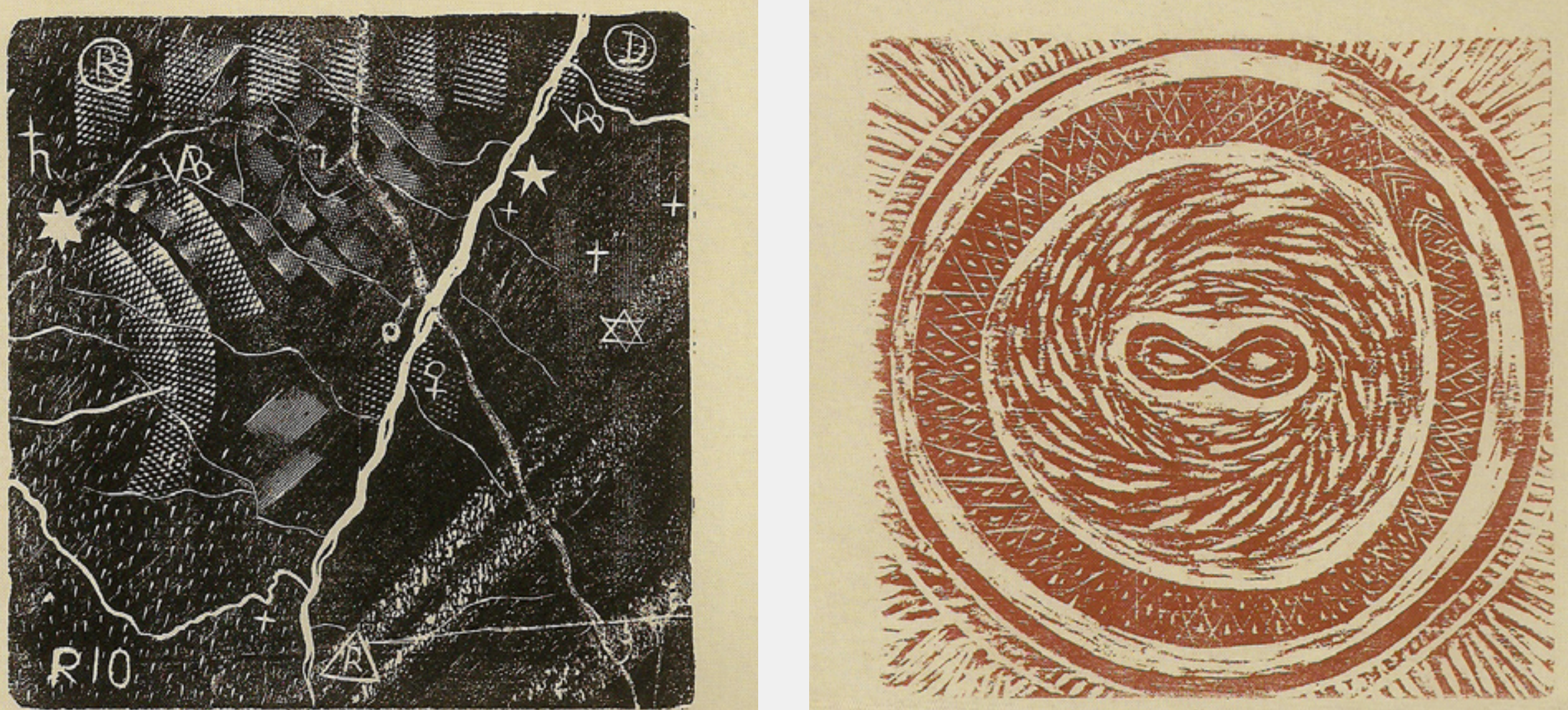

Riobaldo

Xilogravura, tiragem especial PA.II 1984 


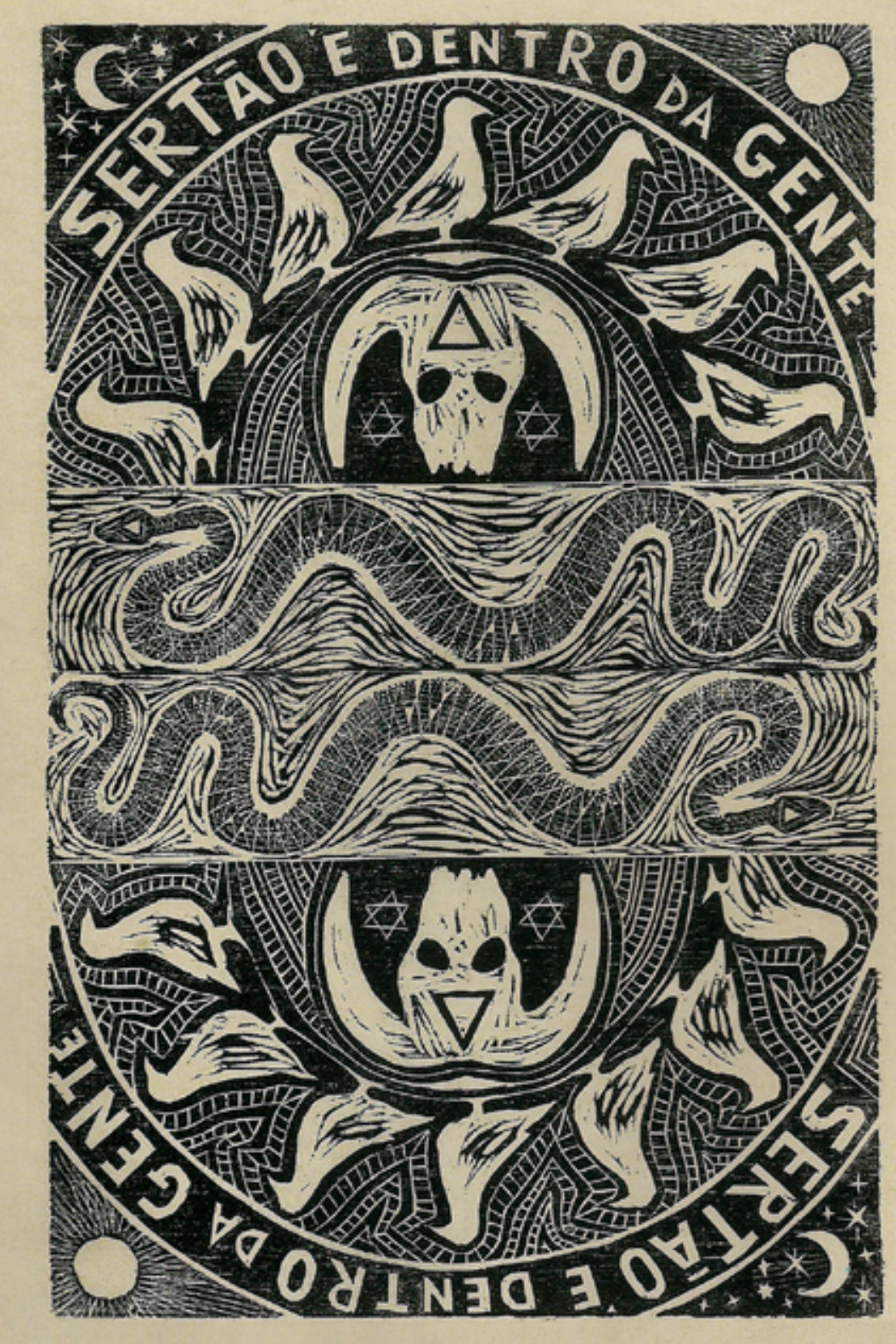

Sertão é dentro da gente 


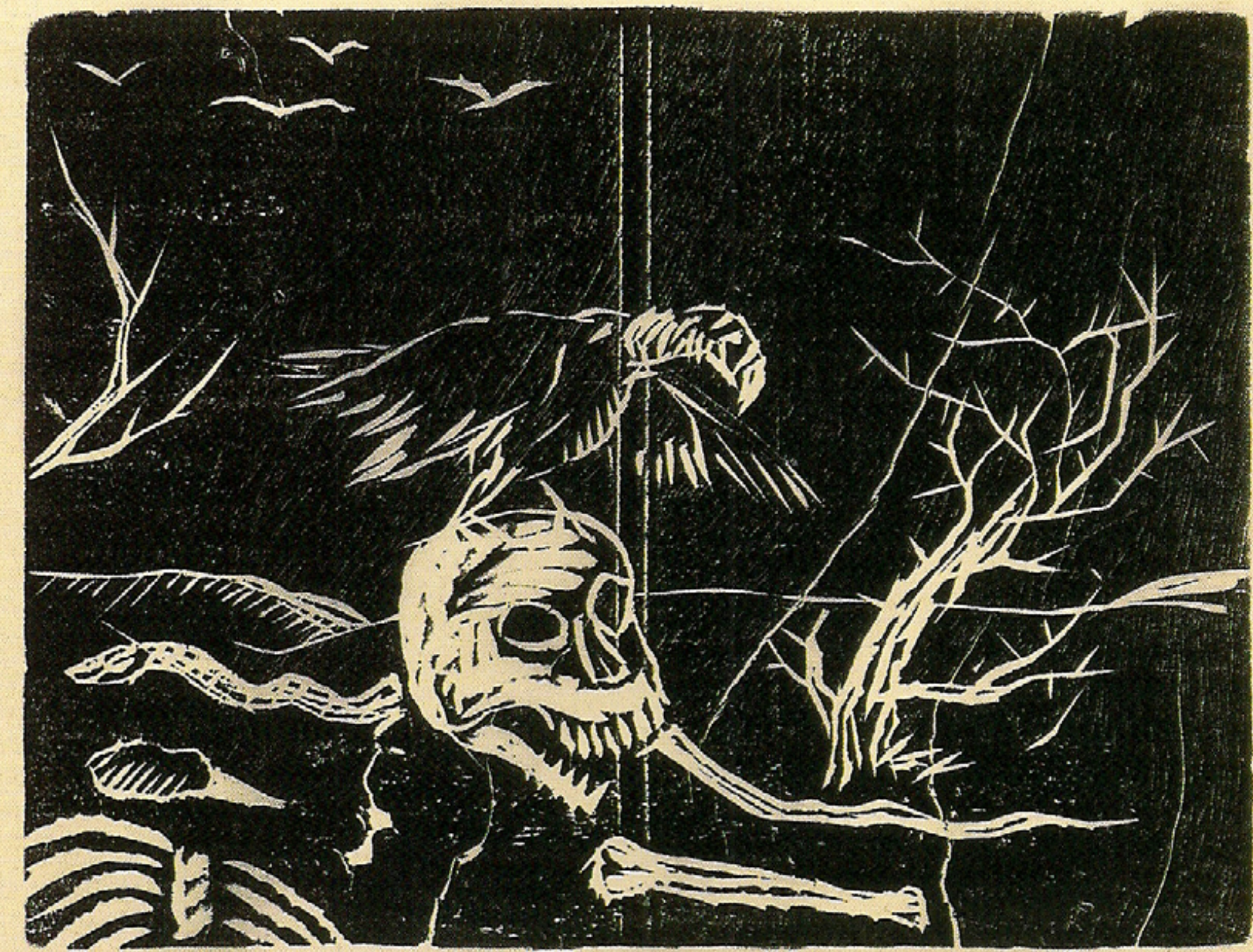

